\title{
Estilos de vida e políticas deliberativas*
}

\author{
Paulo Krischke \\ Universidade Federal de Santa Catarina \\ Cíntia SanMartin Fernandes ${ }^{2}$ \\ Pontifícia Universidade Católica de São Paulo
}

O objetivo deste trabalho é apresentar as reflexões e análise dos debates de um grupo focal misto, entre moradores de alguns bairros populares do Morro da Cruz. Dividimos o trabalho em quatro momentos: o primeiro discute as questões do viver comunitário e o conceito de estilo de vida; o segundo, apresenta a discussão sobre o conceito de comunidade reflexiva; o terceiro problematiza os conceitos de imagem e arte; e, finalmente, o quarto descreve a experiência das comunidades integrantes do Morro da Queimada, no contexto do Maciço do Morro da Cruz, a partir da análise dos grupos e entrevistas realizados ao longo da pesquisa.

Palavras-chave: Estilos de vida Políticas deliberativas - Aprendizado - Comunidade
The aim of this article is to analize the debate of a mixed focus-group of citizens living in some popular neighborhoods of Morro da Cruz, in downtown Florianopolis. The article is divided into four moments. The first one discusses community life and our concept of life-style; the second one discusses the concept of reflexive community; the third one questions the concept of imagery and art; and the fourth one describes the experiences of the communities organized around the Morro da Queimada, that participate in the Maciço do Morro da Cruz, around the analysis of the research groups and interviews.

Keywords: Life-styles - Deliberative policies - Learning - Community

\footnotetext{
${ }^{*}$ Life-styles and deliberative policies

${ }^{1}$ Doutor em Ciência Política pela Universidade de York (Canadá), Professor Colaborador do Doutorado Interdisciplinar em Ciências Humanas (UFSC) e Pesquisador Sênior do CNPq (krischke@cfh.ufsc.br). Versões preliminares deste trabalho foram apresentadas no $33^{\circ}$ Encontro Anual da ANPOCS (Caxambú, Outubro/2009) e no III Seminário Nacional sobre Movimentos SOCIAIS, Participação e Democracia (Agosto/2010). Agradecemos os comentários dos colegas Maria Eunice Maciel e Débora Leitão, Carla Rodrigues e Julián Borba.

${ }^{2}$ Doutora em Sociologia Política pela Universidade Federal de Santa Catarina, tendo feito o Doutorado Sanduíche na Université René Descartes-ParisV/Sorbone, onde participou como pesquisadora no Centre D'etude Sur L'actuel et Le Quotidien (CEAQ), coordenado por Michel Maffesoli. Atualmente realiza Pós-Doutorado em Comunicação e Semiótica na PUC-SP e compõe o quadro de pesquisadores do Centro de Pesquisas Sociossemióticas, coordenado por Ana Cláudia M. Oliveira (PUCSP) e Eric Landowski (CNRS/Paris); também participa do Grupo de Pesquisa Espaço-Visualidade, Comunicação-Cultura (ESPACC), coordenado por Lucrécia D’Alessio Ferrara (PUCSP), e do Grupo de Pesquisa Cidade e Comunicação (UrbCom). (cintia@lagoadaconceicao.com).
} 


\section{Introdução}

Zlorianópolis é constituída por uma variedade de "redes" de comunicação1 comunhão, agentes das escolhas sócio-políticas dos habitantes dos diferentes lugares da cidade. Esses lugares são representativos de modos e estilos de vida diversos que, ao se cruzarem com as questões das deliberações políticas cotidianas das comunidades, utilizam diferentes estratégias de ação política, entre elas a arte, para mobilizar o desejo (pessoal e comunitário) de se expressar nos âmbitos das decisões locais.

Desejo impulsionado, como bem nos apresentou Goethe no século XIX, pelas "afinidades eletivas". Conceito que permeou todo o campo da sociologia compreensiva passando por Simmel, Schutz e Weber e que ganhou força nos estudos contemporâneos ao depararmos com os modos, as formas, as configurações sociopolíticas das comunidades atuais demonstrando que existem em nós - de uma maneira freqüentemente contraditória e inconciliável, escolhas que transitam entre as singularidades e os laços de pertencimento comunitários. Os estudos das representações sociais (JODELET, 2001) constatam que as escolhas deliberativas presentes nas atuais sociedades democráticas expressam cada vez menos etapas de desenvolvimento moral e cognitivo, como as supostas anteriormente pelas teorias de psicologia e sociologia do aprendizado, como os de Piaget, Köhlberg e Habermas (mesmo quando relativizadas como sugeriu CHILTON, 2002).

Diversos estudos, ao contrário, indicam que as formas e mensagens deliberativas de diversos grupos parecem emergir, direta ou indiretamente, dos diferentes estilos de vida e atividades, diversamente priorizados pelos participantes que, em interação com o seu lugar elegem cada um suas afinidades, tanto pelas interações sensíveis como cognitivas - ou seja, o sentido presente nas escolhas emerge das interações ora sensíveis, ora inteligíveis. O sentido compartilhado nas relações sociais nem sempre tem como base ou fundamento uma ação racional instrumental. Muitas escolhas emergem da esfera sensível em que corpo-espírito (razão) não se desvinculam, não se separam. Nesse sentido, o que emerge é um sentir o sentido da vida em comum.

O objetivo deste trabalho é apresentar as reflexões e análise dos debates de um grupo focal misto, entre moradores de alguns bairros populares do Morro da Cruz, selecionados por sua participação em diferentes modalidades de organização popular, e pela vontade que manifestaram de conhecer e trocar informações sobre suas respectivas experiências. Para tanto, dividimos o trabalho em quatro momentos: o primeiro discute as questões do viver comunitário e qual o conceito de estilo de vida que utilizamos; o segundo, apresenta a discussão sobre o conceito de comunidade reflexiva; o terceiro, problematiza os conceitos de imagem e arte; e, finalmente, o último descreve a experiência da 
comunidade do Morro da Queimada, integrante do Maciço do Morro da Cruz, a partir da análise dos grupos e entrevistas realizados ao longo da pesquisa.

\section{O viver comunitário e estilos de vida}

Seja na família, na escola, no grupo do bairro, nos bares que freqüentamos, nos centros culturais que visitamos semanalmente, nos programas que assistimos, nas roupas que vestimos, no corte de cabelo, na pintura corporal, nos pingentes que usamos, na livraria que visitamos, nos cafés em que nos encontramos, no jogo de damas na praça, cotidianamente estamos nos re-encontrando e nos re-afirmando com o outro e através dele. $\mathrm{O}$ sentido buscado nesses lugares pode não ser claro para o indivíduo o tempo todo, porém ele se relaciona todo tempo com essas "imagens" comunitárias.

O importante é sabermos que se ele se relaciona, é porque vê sentido na coisa. Atribui significado ao seu comportamento. Constrói com o outro, e a partir do outro um devir cotidiano. O comum entre eu e o outro, o que nos une, o que nos aproxima em interesses múltiplos (racionais, emocionais, objetivos, subjetivos) é o que dá sentido à nossa existência social, é o que podemos denominar de cultura. Entendemos por cultura o conjunto das práticas e relações sociais e simbólicas de uma determinada sociedade. Ela é dinâmica, híbrida e fluída, o que significa que não existem culturas "puras", intocadas e isoladas. O que nos interessa neste ponto é justamente a hibridez e a diversidade cultural. Tentar compreender o quanto esta diversidade e hibridismo influenciam na possibilidade de transformação da vida cotidiana. Compreender de que forma se dão as fusões socioculturais e no que resultam.

Nesse sentido, Canclini nos apresenta algumas hipóteses em seu trabalho que nos conduzem a refletir sobre as mesmas em nossa realidade social brasileira. Uma hipótese é a de que a "incerteza em relação ao sentido e ao valor da modernidade deriva não apenas do que separa nações, etnias e classes, mas também dos cruzamentos socioculturais em que o tradicional e o moderno se misturam". Outra hipótese importante para nosso trabalho é a de que os estudos transdisciplinares nos auxiliam no entendimento sobre os "circuitos híbridos", onde:

A explicação de porque coexistem culturas étnicas e novas tecnologias, formas de produção artesanal e industrial, pode iluminar processos políticos; por exemplo as razões pelas quais tanto as camadas populares quanto as elites combinam a democracia moderna com relações arcaicas de poder. 
Encontramos no estudo da heterogeneidade cultural uma das vias para explicar os poderes oblíquos que misturam instituições liberais e hábitos autoritários, movimentos sociais democráticos e regimes paternalistas, e as transações de uns com outros (CANCLINI, 2000; pp. 18-9).

\section{A hipótese inicial em nosso trabalho é a de que para haver a fusão é} preciso em primeiro lugar ocorrer comunicação. Neste caso, aludimos ao fato de que nos comunicamos com nossa própria cultura e com diversas culturas numa relação de fala e escuta, através de redes sociais e redes de informação "lugarizadas", localizadas e globalizadas (MORIN, 1995; CASTELLS, 2000; MELUCCI, 1999).

O indivíduo, ou o grupo, movimenta-se através de uma teia repleta de significados e significantes, através de uma rede ${ }^{4}$ que pode conectá-lo a outros indivíduos e grupos. E assim não somente o grupo, mas o indivíduo, pode construir sua própria trajetória, sua própria trilha social, política e cultural tendo a sua frente um tecido social repleto de possibilidades que vão além da cultura "sistêmica". Mas, o quê nos move dentro desta rede?

${ }^{3}$ O lugar pode ser entendido como "espaços afetivos" e de alteridade que se constróem, tomam forma, à medida que são vividos, experienciados, sensivelmente e intelegivelmente por uma prática de reconhecimento resultante de processos de construção identitária (LANDOWSKI, 2002).

${ }^{4} \mathrm{~A}$ idéia de rede implica em admitir a complexidade do social, composto de setores e de grupos heterogêneos, de uma multiplicidade de interesses e contradições, de discursos e culturas plurais, em que opera não apenas a lógica do conflito, como única possibilidade de intervenção crítica, mas em que cada vez mais se descobre a necessidade da cooperação, da solidariedade, e da alteridade.

${ }^{5}$ Aqui estamos nos remetendo à teoria discursiva desenvolvida por J. Habermas (1992, 1984, 1987). Habermas introduz sua concepção de esfera pública trabalhando com duas dimensões existentes na sociedade moderna: a dimensão sistêmica e o mundo da vida. O mundo sistêmico é conformado por uma esfera privada representada pelo mercado, ou seja, esfera da economia, e uma esfera pública representada pelo Estado, ou seja, esfera da política. O mundo da vida ou a esfera da interação comunicativa voltada para o entendimento, é formada também por uma esfera privada, representada pela família, e por uma esfera pública, representada pelas associações e instituições que garantem a reprodução cultural de uma sociedade. Segundo Habermas, para esta opinião pública existir, ela necessita ser primeiramente estruturada e por si mesma, reproduzida à parte do mundo dos sistemas. Essa autonomia só pode ser alcançada através da liberdade de reunião e de opinião. Para isso ocorrer, o autor diferencia os grupos que conformam a esfera pública e atuam na reprodução de suas estruturas, dos grupos que a utilizam enquanto arena capaz de disseminar ideologias e lógicas imperativas do mundo dos sistemas. Assim, a teoria discursiva diferencia a presença de grupos que apenas utilizam da potencialidade comunicativa da esfera pública, dos grupos que fazem uso desta com a finalidade de engajar minorias ou grupos marginais, com a intenção de ampliar as possibilidades públicas de comunicação existentes. O autor assume como premissa o poder da linguagem e da comunicação na formação de uma esfera pública participativa. Para Habermas, a interação comunicativa voltada para o entendimento está presente no mundo da vida, e para que se dê esta interação é necessário que os indivíduos abram mão de alguns pressupostos iniciais que fazem parte de sua vida privada, para introduzir demandas no espaço da discussão. Segundo Habermas, esta "abertura" não acontece no mundo dos sistemas econômico e político, pois estes não abrirão mão de seus pressupostos iniciais para a conquista de um fim social. 
A pulsão é o que nos move. Como um bater do coração que a cada segundo faz com que o sangue jorre em nossas veias nos re-alimentando, nos re-energizando, nos re-limpando, nos re-ligando à vida, nos re-ligamos ao nosso lugar, à nossa comunidade através das imagens presentes e apresentadas nela. Necessitamos dos signos e dos símbolos para nos posicionar e agir dentro de nossa comunidade. Desta forma podemos falar que existem diversas comunidades, ou tribos 6 , dentro "da sociedade". E que cada uma compartilha não somente dos símbolos e significados da cultura "sistêmica", pois negocia com ela, como cria os seus próprios símbolos e significados culturais diversos daqueles. Ou seja, há um movimento intenso, há uma relação quase que frenética, entre representações culturais "sistêmicas" e vida cotidiana. Concordamos com Martins no momento em que nos afirma que:

\begin{abstract}
Mais do que uma coleção de significados compartilhados, o senso comum decorre da partilha, entre atores, de um mesmo método de produção de significados. Portanto, os significados são reinventados continuamente em vez de serem continuamente copiados. As situações de anomia e desordem são resolvidas pelo próprio homem comum justamente porque ele dispõe de um meio para interpretar situações (e ações) sem sentido, podendo, em questão de segundos, remendar as fraturas da situação social (MARTINS, 2000; p. 61).
\end{abstract}

A tarefa tanto do grupo como do indivíduo é estabelecer o seu reconhecimento e encontrar suas representações, ajudando também a construí-las no dia-a-dia, dentro desta sociedade que contém diversas comunidades. E esta integração, esta relação simbiótica entre o indivíduo e as representações políticas e socioculturais se estabelecerá num primeiro momento através da imagem e das expressões artísticas impressas no corpo social cotidiano.

Assim, entendemos que a comunidade pode pulsar com maior ou menor intensidade. Pode de quando em quando se deparar com uma artéria entupida e criar mecanismos de escape, procurando outros caminhos, novas alternativas,

\footnotetext{
${ }^{6} \mathrm{O}$ conceito de tribalismo é introduzido na discussão sociológica por M. Maffesoli em seu estudo a respeito do declínio do individualismo nas sociedades de massas neste fim de século. Este estudo aponta a emergência de micro-grupos sociais, os quais denomina "tribos". Para o autor, a metáfora da tribo "permite dar conta do processo de desindividualização, da saturação da função que lhe é inerente, e da valorização do papel que cada pessoa (persona) é chamada a representar dentro dela. Claro está que, como as massas em permanente agitação, as tribos que nelas se cristalizam tampouco são estáveis. As pessoas que compõem essas tribos podem evoluir de uma para outra" Maffesoli,M. O Tempo das Tribos: o declínio do Individualismo na Sociedade de Massa. P. 9. Rio de Janeiro: Forense, 1987.
} 
novas formas de caminhar e de se revigorar. E para que haja um movimento do grupo é necessário que exista um mecanismo de comunicação dos membros entre si. Como em nosso organismo, onde uma veia se comunica com outra, que se comunica com artérias que se comunicam com veias, como uma fiação interna de um sistema eletrônico, a comunidade se comunica em rede e por rede ${ }^{7}$.

Mas, como se dá esta comunicação, sendo que as redes apresentam nódulos (que representam semi-centros) e ramificações? Ou seja, o que nos interessa é: como na diversidade das sociedades pós-modernas (plurais), onde a reflexividade se constrói individualmente para depois ser socialmente construída, se organiza um agir comunicativo que é coletivo? Como, e de que forma, mesmo diante da heterogeneidade e atomização societária, construímos um viver comunitário, onde a perspectiva do ser-em-comum, respeitando a diversidade, é a tônica desta relação? Pode a arte de fato possibilitar a construção de uma nova socialidade? De que modo? A rede social e técnica são fundamentais para a consolidação dessa socialidade?

E é justamente no dia-a-dia, nos espaços públicos primários ${ }^{8} \operatorname{como}$ praça, o campo, a rua, o parque, o baile que nos distanciamos do mundo racional instrumental, construindo e reconstruindo as regras morais, culturais e sociais mais próximas de nossa realidade. Nestes espaços é que podemos compartilhar histórias de vida, gestos, sentimentos, hábitos, comportamentos e ações. É nestes espaços que nos olhamos de frente, muitas vezes de forma nebulosa, pois o outro também possui suas incertezas, incongruências, suas perversidades. E é justamente nesses espaços do cotidiano que podemos encontrar as riquezas dos fios que tecem e tramam o tecido social. Nestes espaços podemos encontrar as expressividades mais sublimes dos indivíduos onde inclusive estes podem exercer uma comunicação livre de qualquer vigilância das estruturas de poder (nos remetemos aqui às estruturas de poder apresentadas por Foucault), onde os conteúdos comunicativos são produzidos a partir de seu exercício reflexivo cotidiano.

O estilo aqui é visto diferentemente das pesquisas realizadas, nas décadas de 1960 e 70, pelo Centre of Contemporary Studies da Universidade de Birmingham, em que os pesquisadores desenvolveram o conceito a partir da noção de "sub-cultura" (HERSCHMANN, 2000). O chamado "estilo de vida" foi compreendido tendo como balisa comparativa os referenciais da cultura hegemônica.

\footnotetext{
${ }^{7}$ Estamos utilizando o conceito de rede como um tipo de relação social. O que parece interessante é observarmos como se desenvolve e se entra nos espaços de comunicação intra-rede. Como se organiza uma nova rede de comunicação (não essencialmente atrelada à técnica) e a capacidade simbólica de cada grupo, de cada movimento, de cada organização social dentro da sociedade.

${ }^{8}$ Por espaços públicos primários entende-se aqueles espaços do encontro público como a rua, a praça, a fogueira, os bares etc de uma comunidade. De acordo com Costa (1997), há quatro campos constitutivos dos espaços públicos locais: os meios de comunicação de massa, a esfera estatal-parlamentar, os espaços públicos vinculados aos grupos organizados e os espaços comunicativos primários.
} 
Opondo-se a esta idéia de subculturas entendemos que o estilo pode ser compreendido como reconhecimento das práticas sociais locais que se estruturam a partir de repertórios socioculturais dentro de uma dinâmica que estabelece dialogia entre valores e referenciais políticos, sociais, econômicos e culturais entre o lugar, o local e o global.

Pensemos o estilo como "um conjunto de formas ordenadas" uma verdadeira concepção geral da vida, não pretendendo ser eterna mas fonte de uma agregação coletiva, um sentir, fazer, ser e estar compartilhado, experimentado como uma espécie de "língua comum". Como um gênero de linguagem em que existimos no e pelo olhar e a palavra do outro. Assim nos aproximamos, como afirma Maffesoli, do interesse sociológico em investigar a dialética "entre o fundo e a forma, da qual o estilo é expressão".

Pouco importa o termo empregado: ideal-tipo (Weber), resíduo (Pareto), caráter essencial (Durkheim), estrutura (Lévi-Strauss), arquétipo (G. Durant), o essencial é destacar um denominador comum capaz, senão de explicar a época em sua totalidade, de pelo menos desenhar seus principais contornos. Desse ponto de vista, o estilo é uma alavanca metodológica privilegiada: ele acentua, aumenta, caricatura, e desse modo valoriza o que se tem, por hábito moralista, demasiada tendência a negligenciar. (MAFFESOLI, 1995; p. 37).

Propomos pensar os estilos de vida, seguindo essas pistas, compreendendo-o como o élan comunitário cristalizado em cada indivíduo de determinado grupo social. Cada indivíduo carrega valores e sentidos compartilhados pelo grupo possibilitando assim entendermos por meio deles, de suas marcas, as distinções das práticas socioculturais da contemporaneidade. Ou seja, o estilo não pode ser pensado distante da ética e estética (não reduzida a arte, mas como emoções partilhadas, aisthesis) de uma época, de um lugar.

\section{Reflexividade e Comunidade}

Será a partir da relação com o grupo, que o indivíduo constituirá aquilo que autores como Anthony Giddens e Ulrich Beck ${ }^{9}$ denominaram de reflexividade. Porém, a reflexividade a que nos referimos se distancia um pouco desses autores. Não é algo que está dado a priori ou algo que possua um valor cumulativo e que se desenvolve num movimento de individualização, mas sim algo que se constrói no dia-a-dia e que não necessariamente possui um caráter evolutivo individual.

\footnotetext{
${ }^{9}$ Este debate também está presente na Teoria Social Brasileira. Autores como José Domingues, Jessé de Souza, Sérgio Costa e Leonardo Avritzer vêm refletindo sobre a modernidade e a possibilidade de estarmos, enquanto país, incluídos ou não neste projeto. No cerne do debate encontramos a questão da reflexividade, da democracia racial, da diversidade cultural, entre outros temas e conceitos relacionados à reflexão sobre os dilemas da modernidade (ver I. Scherer-Warren, S. Costa \& H. Leis (Orgs.). Modernidade Crítica e Modernidade Acrítica. Florianópolis: Cidade Futura, 2001).
} 


\title{
HUMANAS
}

Algo que existe porque os indivíduos pensam, sentem, agem e estabelecem trocas concretas e simbólicas com o grupo cotidianamente.

Não somente o conhecimento (reflexividade cognitiva) flui pelas estruturas de informação e comunicação, como também os signos, as imagens, os sons etc. Esta outra estrutura se caracteriza por símbolos miméticos e podemos denominá-la, seguindo Scott Lash, de reflexividade estética onde:

\begin{abstract}
Os símbolos conceituais, os fluxos de informação através das estruturas de informação e comunicação, certamente, tomam dois atalhos. Por um lado, representam um novo fórum para a dominação capitalista. Neste caso, o poder está mais fundamentalmente localizado no capital como meio de produção material... Está baseado no complexo poder/ conhecimento... do modo da informação. Por outro lado,... estes fluxos e acumulações dos símbolos conceituais constituem condições de reflexividade. O mesmo acontece em relação aos símbolos 'miméticos', às imagens, sons e narrativas que compõem o outro lado da organização de sinais... Eles abrem espaços virtuais e reais para a popularização da crítica estética desse mesmo complexo poder/conhecimento (LASH, 1997; p. 164)
\end{abstract}

Podemos atribuir à reflexividade estética a defesa de que a cultura popular pode servir não à dominação, mas a uma cultura de resistência; assim estaríamos superando os impasses de Adorno a respeito da incapacidade da cultura popular ser uma cultura crítica capaz de produzir para além das estruturas de poder/conhecimento do sistema.

Como pode a estética, um momento estético ou uma fonte estética, de per si ser reflexivo? Pode haver reflexividade tanto nos mundos sociais e psíquicos naturais da vida cotidiana, como no sistema? Podemos afirmar que há dois "níveis" de reflexividade que se interpõem na vida cotidiana: cognitiva e estética (LASH, 1997:164). A reflexividade estética ocorre através de um modo de mediação não conceitual, mas mimético. O que não deixa de ser tão ou mais importante que a reflexividade cognitiva. A reflexividade estética nos conduz à possibilidade de compreendermos a comunidade em questão, o seu momento, a sua lógica local, o seu viver cotidiano.

Lash nos aponta que:

Para se ter acesso ao nós, à comunidade, não devemos desconstruir, mas hermeneuticamente interpretar e, assim, abandonar as categorias de 
ação e estrutura, sujeito e objeto, controle versus contingência e conceitual versus mimético. Este tipo de interpretação vai dar acesso aos fundamentos ontológicos, em sitten, em hábitos, em práticas assentadas de individualismo cognitivo e estético. Isso, ao mesmo tempo, vai nos proporcionar algum entendimento das significações compartilhadas da comunidade (LASH, 1997; p. 175)

O que devemos é olhar com mais atenção para o mundo cotidiano e nele compreender hermenêuticamente, os significados compartilhados que são as condições de existência do "nós". Neste sentido, nossa proposta é a de uma reflexividade hermenêutica em contraposição às teses da reflexividade exclusivamente estética ou especialmente cognitiva. Nestes termos, nos aproximamos do conceito de "comunidade reflexiva" de Scott Lash, onde há três fontes muito importantes para o self contemporâneo, que são analiticamente separáveis, como "momentos" cognitivo, estético e hermenêutico-comunitário. "Momentos" que existem em nós de uma maneira frequentemente contraditória e inconciliável, onde os indivíduos navegam entre suas singularidades e os laços de pertencimento comunitários.

\section{Imagem e arte como símbolo da pulsão cotidiana}

O problema é que a modernidade nos apresentou a imagem como uma "corruptora das almas". A partir do Iluminismo, o discurso a respeito da função perversa da imagem na vida social se tornou quase que unânime nos discursos das ciências sociais. Tão presente e tão bem estruturado foi este discurso ao longo do século XX, que o senso comum passou a se apropriar dele se tornando tema de encontros casuais.

Afinal de contas, para que nos serve a imagem? Qual é o feitiço que causa nas pessoas? Porque não a aceitamos como uma representação de nossos tempos? Devemos nos lembrar que a imagem não é una, é múltipla e facetada. Ela não é refém de uma classe social, de um credo, de apenas um grupo. Ela está presente em tudo e em todos. Nós somos também imagem. Nós somos responsáveis pela construção e desconstrução dos sentidos das imagens que estão aí presentes na vida social. Através delas é que nos apresentamos, nos comunicamos, nos reconhecemos, nos tribalizamos. Nos gestos, nas cores, nas roupas, em todos os símbolos que administramos cotidianamente a imagem é o que nos apresenta ao mundo. Então, ao invés de temê-la devemos observála e tentar compreendê-la. 


\section{Hüüăas}

A modernidade construiu um discurso em que a imagem poderia ser a responsável pela homogeneização da sociedade. Ora, não seria o próprio projeto moderno homogeneizador da vida social? A ambivalência e a contingência foram esquecidas pelos projetos modernos. Houve uma tentativa de ruptura com tudo o que não se enquadrasse na chamada vida moderna. O ufanismo político em nome da construção do cidadão apresentou a possibilidade de apenas um único projeto político-social e cultural. O aniquilamento da vida comunitária em nome da construção de uma sociedade de indivíduos livres e racionais negou a muitos a possibilidade de fazerem parte deste projeto, ou deste processo "civilizador".

A imagem fora utilizada pelos executores do "projeto modernidade", porém os indivíduos que a receberam e a aplaudiram visionaram este mundo como representante das suas expectativas de vida social; mais ainda, essas pessoas foram também responsáveis pelas imagens. Nelas se viam, davam sentido e significado para que continuassem existindo.

Com isso podemos afirmar que outras imagens não co-existiram com a imagem do projeto da modernidade? Não. É só olharmos para o tecido social que encontramos a resposta. É justamente na vida cotidiana que observamos rupturas, que observamos o quanto há a necessidade de não reprodução, da fuga da mesmice, que observamos momentos de transgressão, de ousadia, de atrevimento, de descobertas e de invenções. É na vida cotidiana que podemos observar a emergência de novas alternativas culturais.

Nestes termos gostaríamos de tratar da imagem não como a "louca da casa", mas assim como nos aponta Maffesoli (1995), como 'religante'. Religante por me unir ao mundo que me cerca, por me unir aos outros que me rodeiam. Para o autor:

A imagem não é simplesmente um suplemento da alma, algo na melhor das hipóteses dispensável, na pior, primitivo ou anacrônico, mas, ao contrário, ela está no próprio âmago da criação, ela é verdadeiramente uma 'forma formante', certamente do indivíduo: a imagem de si, mas igualmente de todo o conjunto social que se estrutura graças e pelas imagens que ele se dá, e que deve rememorar regularmente. Mesmo que isso não seja formulado dessa maneira, um e outro irão viver arquétipos fundadores; e sua vitalidade será medida pela fidelidade a esses arquétipos. E, quando estes perdem sua força, o corpo social ou o corpo individual tende a enfraquecer, às vezes, até mesmo a desaparecer, até que outras imagens venham renegar o corpo em questão (MAFFESOLI, 1995; p. 115). 
Desta forma a imagem, o imaginário, o simbólico suscitam essa confiança mínima, que permite o reconhecimento de si a partir do reconhecimento do outro, seja qual for o estatuto do "outro" (indivíduo, espaço, objeto, idéia etc.); ou seja, a imagem nos religa ao mundo e aos elementos deste mundo de maneira específica, como por exemplo através da religião e da moda. Podemos afirmar então que a imagem liga os grupos de pessoas que compartilham do mesmo significado frente à vida. E ao ligar estas pessoas através de uma razão que pode ser tanto emocional, como objetiva, como espiritual, como estética, ela cumpre um papel de me religar a vida em sociedade, de dinamizar o estarjunto. É nesse sentido que a imagem faz cultura.

Ou seja, a imagem transmite/constrói conceitos culturais de uma época histórica. De certa forma, é na imagem que encontraremos a nossa referência individual e social, é ela que nos remete ao passado e ao futuro. É através dela que tocamos no presente e na vida cotidiana:

A imagem é tempo "esteinizado", que se contrai. Nesse sentido, o amor pelo distante, pela cidade ou vida porvir, ou seja, o político, transforma-se em amor pelo próximo, pelo que está aí, por aquilo que se vê (imagem), por aquilo que se toca (o objeto, o outro), isto é, pelo doméstico. É essa inversão, essa transfiguração, que favorece os diversos apegos ao território, aos objetos, às relações próximas e vicinais, às diversas "aldeias" ou tribos das quais somos membros por mais de um motivo, em todos os domínios. É isso mesmo que engendra a religiosidade, o simbolismo de que é forjada a vida social, e que faz com que esta não mais obedeça às injunções racionalistas com predominância político-econômica (MAFFESOLI, 1995; p. 133).

Essa transfiguração do político, essa aproximação do político às vidas das pessoas, esse estímulo à afetividade, é o que as possibilita utilizar das imagens, das artes, como uma fonte de expressão da diversidade cultural do país. Os movimentos culturais ${ }^{10}$ que emergiram em nosso país a partir da década de 1980 vêm nos demonstrar como vivemos uma realidade complexa, carregada de códigos culturais diversos e repleta de sinais que nos levam a concluir que a arte pode estar se constituindo numa ferramenta do fazer política, não a política representativa-racionalista da democracia que convivemos desde o século XVIII, mas uma política que tem seus pés fincados no cotidiano.

\footnotetext{
${ }^{10}$ Os movimentos como hip-hop, funk, mangue-beat, rap, e projetos nos morros da Mangueira e da Rocinha, no Rio e do MIAC em Salvador que estimulam a transformação do cotidiano através da arte, são exemplos do que estamos pontuando acima. Ver: Fernandes (2008) e Herschmann (2003).
} 
Estudos recentes no país confirmam este movimento de integração entre a vida cotidiana e as ações sócio-políticas.

Ikeda (1995) nos apresenta argumentos fortes neste sentido, ao estudar a música, como mediação entre a criatividade do cotidiano, e a vida institucional, dentro do campo das artes, ele nos mostra que esta se apresenta em praticamente todos os grupos humanos - do tribal à sociedade tecnológica - como elemento de mediação das relações internas e externas das sociedades; como elemento que pode se revestir em si de sentido político, Hershmann (2003), aprofunda esse argumento ao analisar a dinâmica da violência urbana por meio do campo da cultura do Hip-Hop e do Funk. Seu estudo trouxe à cena elementos importantes para o debate sobre representações sociais, violência, cultura popular e participação política. Uma das hipóteses apresentadas é a de que os jovens que participam desses movimentos artísticos colocam em evidência, através de suas músicas, questões fundamentais a respeito da desigualdade social, política e econômica do país; desenvolvendo uma política cotidiana que acessa as sociabilidades mais rotineiras. Uma atuação política não necessariamente vivida num primeiro plano, mas que se faz presente em seus estilos de vida, fortalecendo o reconhecimento e os referenciais identitários dessas tribos.

Fernandes $(2005,2008)$, ao se debruçar nas experiências de um movimento social da cidade de Salvador, na Bahia, o Movimento de Intercâmbio Artístico Cultural pela Cidadania (MIAC) demonstrou como redes sociais e manifestações artísticas ampliam as possibilidades de comunidades se organizarem em movimentos que invadem, ocupam a cidade com a arte, assumindo lugar nas esferas públicas participativas. Seu trabalho apresenta como a associação entre arte, pluralidade cultural e demandas sociais foram os instrumentos utilizados pela "rede em movimento" para redesenhar a forma de atuação política nos espaços públicos soteropolitanos em nome dos direitos humanos e cidadania para crianças e adolescente. A partir dessa experiência confirma sua hipótese de que a nova dinâmica de sociabilidade no contexto da pós-modernidade, reflexo de um deslocamento da política - antes centrada em instituições identitárias fixas da modernidade, como partido político, sindicato, classe, gênero etc. -, centra-se num agir comunicativo que considera tanto as estratégias racionais dos indivíduos como o imaginário comunitário com base numa razão sensível.

Esses estudos auxiliam as reflexões e análise dos debates de um grupo focal misto, entre moradores de alguns bairros populares do Morro da Cruz, em Florianópolis, Santa Catarina, selecionados por sua participação em diferentes modalidades de organização popular, e pela vontade que manifestaram de conhecer e trocar informações sobre suas respectivas experiências. Os resultados iniciais indicam que as opiniões políticas encaminhadas por esses moradores, as formas e mensagens deliberativas do grupo parecem emergir, direta ou indiretamente, dos diferentes estilos de vida e atividades, priorizados por cada participante. 


\section{A experiência do Morro da Queimada}

Sabemos que o clientelismo da política tradicional brasileira fragmenta as comunidades de baixa renda, estimulando os indivíduos a que culpem a si mesmos pelos problemas que enfrentam, e a competir com os demais indivíduos para tentarem melhorar de vida. As respostas dos setores "progressistas" (ou "de esquerda") a essa política tradicional busca incentivar a unidade, a cooperação, a organização e a "consciência coletiva" entre os participantes das comunidades populares. Mas sabemos também que estas respostas digamos "coletivistas", raramente funcionam, ou ocorrem apenas de modo muito parcial ou temporário. Daí a tendência destes setores a recair na mesma tautologia conservadora, que pretenderiam superar - ou seja, tendem também a "culpar as vítimas" por seu individualismo tradicional, alienação e "falta de consciência" coletiva, etc. (por exemplo: "as comunidades não se organizam por que são desorganizadas").

Esta pesquisa realizou estudos com grupo focal nas comunidades do Morro da Queimada e adjacências em Florianópolis. O tema focal deste grupo foi a avaliação que fariam do "Fórum das Comunidades do Maciço" - o qual reuniu em seu momento a maioria das comunidades dos morros e tem exercido forte influência sobre as escolas públicas que atendem as crianças desses bairros. O suposto da pesquisa foi que este Fórum estaria sendo muito importante no processo de organização coletiva das comunidades, promovendo a superação do clientelismo individualista e competitivo, que sempre marcou a trajetória anterior destas comunidades. No ano anterior o governo já iniciara a implementação do Programa de Aceleração do Crescimento (PAC), com recursos federais para a urbanização de algumas comunidades do Maciço; a equipe decidiu então realizar um grupo focal, nas comunidades do Morro da Queimada e adjacências, que focalizasse tanto o Fórum como outras formas de atuação e orientação existentes nessa área.

Participaram lideranças da associação da Queimada, uma das comunidades contempladas pelo PAC - os quais são membros ativos do Fórum e do comitê gestor do PAC; líderes da associação de moradores da comunidade José Mendes (que ocupa a base desse morro, circundando o túnel que liga o centro à Via Expressa Sul); além de líderes de uma cooperativa local que fabrica, com apoio do governo, aquecedores solares para as novas residências construídas pelo PAC; finalmente, participaram também jovens treinadores da Casa Brasil, organização não-governamental subsidiada com recursos federais e que oferece aos jovens do local programas de esporte, lazer e acesso à informática. Todos foram convidados ao grupo como uma oportunidade para tornarem conhecidas pelos demais, as atividades que realizam. Isto garantiu que o grupo demonstrasse uma dinâmica muito vibrante que logo comentaremos, em parte resultante da surpresa e curiosidade de todos acerca daquilo que desconheciam, nas falas dos demais. 
Veremos também que apesar das diferenças entre essas atividades, houve algumas convergências no grupo sobre temas e problemas comuns, e suas possíveis soluções. Estas circunstâncias conferiram ao grupo uma eficiência prática e fluidez nos debates, que de outra forma seria difícil atingir. Na verdade, o grupo revelou que mesmo os líderes de associações mais antigas e experientes abdicavam das costumeiras "verdades" conquistadas na trajetória de suas comunidades. Por exemplo, reconheceram as ilusões que tiveram antes, sobre a pretensa autonomia do Fórum, que as obras do PAC eram como sempre controladas pela prefeitura municipal, e que cabia agora fiscalizar o "pós-PAC" para buscar estender os benefícios às demais comunidades, cujos vizinhos se interessarem.

A teoria do desenvolvimento moral-cognitivo presumivelmente atribuiria ao posicionamento dos líderes da Queimada uma capacidade universalista "pós-convencional", por sua capacidade de autocrítica e avaliação reflexiva das próprias normas, dominantes ou não, que têm defendido no decorrer da experiência. Isto já tem acontecido em outras experiências (KRISCHKE, 2003). Esta capacidade foi reconhecida e respeitada no próprio grupo focal, por participantes que também em parte denunciaram a continuidade das práticas clientelistas das autoridades e lideranças. Mas o grupo foi além, no sentido de exercer internamente normas paritárias de interação, cobrando a todos os participantes sua opinião e desempenho cooperativo (FRASER, 2003).

Esta cobrança não teve o sentido coletivista anteriormente tentado, e fracassado com o Fórum, mas um novo significado aberto ao futuro, de uma negociação e cooperação em andamento. Por exemplo: como fazer que as escolas públicas da área, cujo desempenho tem sido benéfico e organizado coletivamente pelo Fórum, possam abrir suas portas nos finais de semana, para acolher atividades de esporte e lazer da juventude? Foi levantada a necessidade de garantir a segurança para preservar o patrimônio público, mas também foi lembrado o remanejo e ocupação de outros espaços públicos, como o do futuro parque do PAC no Morro - e a urbanização da praia e do aterro, tal como já tem sido testada nas festas da associação do José Mendes.

Todos lembraram a importância das festas e esportes como formas de lazer e recreação necessárias às comunidades. As escolas de samba têm importância reconhecida na área, a os apoios que recebem de políticos e traficantes são notórios nas comunidades. O mesmo acontece no reconhecimento do papel central das religiões, e na participação dos políticos nas procissões, etc. Porém, no caso do José Mendes se enfatiza o caráter espontâneo das artes, artesanato, festas cívicas e religiosas, e a possibilidade de promover isso nas comunidades, como forma de desenvolvimento da área, definir sua identidade frente ao restante da cidade, atrair turismo e comércio local. 
Tudo isto mostra a abertura do grupo a uma cooperação multi-setorial abrangente, que não aparece subordinada a nenhum tipo de hierarquia política ou social. Esta hierarquia está normalmente presente entre as lideranças dos bairros - que privilegiam atores masculinos, religiosos, partidários ou profissionais, de diferentes áreas ou instituições, do governo ou da sociedade, aos quais se atribui a resolução clientelista de todos os problemas.

Ao contrário, os participantes do grupo apresentam-se, e reconhecem aos demais, como dotados de uma condição pessoal, que os habilita a deliberar no grupo. Condição que é a de um morador responsável, que quer ajudar a decidir e a resolver, com sua própria opinião e intervenção, aquilo que for visto pelo grupo como prioritário e passível de solução na vida do bairro. Não será demais sugerir, que estas características das políticas deliberativas do grupo relacionam-se aos estilos e formas de vida, que os participantes adotam no seu cotidiano, e também nos modos de organização das atividades que escolhem realizar, principalmente aquelas que envolvem a arte como forma de enunciação e comunicação sócio-comunitária.

O que conseguimos compreender, a partir dos grupos e entrevistas, é que há uma tendência forte para mudança na organização comunitária dos moradores, no que diz respeito à luta cotidiana contra a dominação dos políticos tradicionais quando se trata da busca de soluções para os problemas do Morro. A luta pela liberdade e independência comunitária de atuação política decisória se faz presente nas falas e nas expressões artísticas. E é interessante recordar que a maioria dos participantes no estudo atua em projetos fortemente relacionados com o governo federal. Porém não parecem fazer disso uma bandeira ou garantia para resolução dos problemas, e antes o consideram direito adquirido, forma de reconhecimento, e incentivo a que eles próprios elaborem os seus caminhos e realizações.

Ou seja, esses moradores estão longe de aceitar, e ao contrário rejeitam, uma relação de clientelismo ou dependência das comunidades e indivíduos, frente às autoridades e o governo. Talvez seja esta apenas uma tendência nascente, que constatamos agora mas que poderia ser afinal derrotada. Porém, constitui inovação significativa, contra o marasmo e a mesmice da política tradicional brasileira.

\section{Descrição do Maciço do Morro da Cruz}

A seguir alinhamos alguns dados e informações adicionais, que podem ajudar na compreensão deste texto. O Maciço do Morro da Cruz é uma elevação rochosa de cerca de 280m, situada na área central da cidade de Florianópolis, junto às pontes que ligam a ilha ao continente. Estima-se que há cerca de $30 \mathrm{mil}$ habitantes nas 21 comunidades de baixa renda que circundam o Morro da Cruz. 
Nota-se no mapa a fragmentação física entre as comunidades, afastadas pelos blocos de pedra do cume do monte, onde se encontram as antenas de televisão.

Várias dessas comunidades estão interligadas apenas à via central do bairro, que comunica cada bairro com o centro da cidade. Até pouco tempo não havia clara distinção entre as comunidades do Morro e os bairros circundantes oficialmente reconhecidos pelo IBGE. Nessas comunidades existem situações de elevado risco de deslizamento do solo, que muitos setores da população encaram com relativa naturalidade, face ao que lhes parece ser certa inevitabilidade das catástrofes iminentes, que afligem o seu cotidiano habitual. Contudo, essas comunidades geram atividades artísticas que enriquecem o patrimônio cultural da cidade, como as duas Escolas de Samba, entre as quatro que disputam a supremacia do Carnaval todos os anos. Uma das questões iniciais motivadoras da pesquisa foi: como é possível que esses moradores das comunidades, que revelam esse grande talento e capacidade de iniciativa ("riqueza cultural") tenham de conformar-se na vida cotidiana, com suas condições de "pobreza política", exclusão social e econômica?

Essa questão passou a não fazer mais sentido no momento em que adentramos a comunidade e realizamos a pesquisa. A comunidade não está conformada, ao contrário, luta cotidianamente para ampliar sua participação decisória, no entanto existem barreiras clássicas advindas das práticas clientelistas tanto dos representantes do governo municipal e estadual quanto das lideranças comunitárias que se institucionalizaram assumindo o discurso paternalista e assistencialista. Essa prática é danosa, pois aparentemente "desmobiliza" a participação popular. Mas o que encontramos é uma força mobilizadora comunitária que atua ora aceitando os discursos assistencialistas, ora tentando afastar-se deles em busca de uma "autenticidade" comunitária capaz de representá-los a partir de sua prática sociocultural local.

É importante salientar a presença de práticas religiosas no Morro. Há presença de todas as religiões, no entanto as duas mais citadas pelos moradores que sobressaem no cotidiano da comunidade são a católica e a espírita (umbanda e candomblé). Há um número grande de católicos tradicionais, que participam das celebrações religiosas de origem açoriana seguidas por muitos habitantes de Florianópolis. Nessas cerimônias estão em geral presentes os políticos conservadores, como o ex-governador Espiridião Amin e o prefeito da capital.

O vínculo religião/política não ocorre apenas pela via político-partidária. Há cerca de vinte anos um sacerdote católico (Padre Wilson Gröh) passou a morar numa das comunidades do morro, participando ali de um processo de organização comunitária que se tornou paradigmático para o restante das comunidades. É interessante observar que essa ativação religiosa reuniu muitos membros da comunidade, mas também entrou em competição com representantes das autoridades políticas, e cabos eleitorais de vários candidatos e partidos. 
Quando esse sacerdote iniciou suas atividades no Morro, moveu oposição aos governos e políticos conservadores e com isso iniciou uma polarização entre as comunidades, que até hoje tem sido difícil superar.

Mais recentemente, se iniciou a formação de comissões de moradores através das escolas que atendem as famílias do Maciço, o que tem ajudado a despolarizar a competição entre as comunidades de moradores. Essas comissões foram gradualmente nucleando os interesses das comunidades, de modo a superar sua fragmentação e vulnerabilidade à dominação clientelista dos políticos e partidos conservadores. As demandas pela contenção das encostas e a proteção dos direitos ambientais, por exemplo, mobilizaram as negociações com a prefeitura municipal, gerando a partir daí a criação do FORUM de Comunidades do Maciço, responsável por encaminhar e negociar essas e outras demandas das comunidades.

Nesse processo de negociações surgiu a demanda por uma legislação municipal que decretasse o Morro da Cruz como parte de uma ZEIS (zona de especial interesse social), de modo a permitir a regularização fundiária, a ocupação legal do solo, e o acesso aos serviços básicos que correspondem ao zoneamento urbano. A Regularização Fundiária é o processo de intervenção pública, sob os aspectos jurídico, físico e social, que objetiva legalizar a permanência de populações moradoras de áreas urbanas ocupadas irregularmente para fins de habitação, implicando acessoriamente melhorias no ambiente urbano do assentamento, no resgate da cidadania e da qualidade de vida da população beneficiária. A conquista dessa lei tem suscitado outras demandas e manifestações, junto à secretaria de habitação da prefeitura, como o acesso das comunidades a água tratada e aos espaços de lazer comunitário.

Outra frente em que as comunidades têm atuado é a resistência à rede de narcotraficantes, que recruta muitos jovens das comunidades para tarefas de vigilância e distribuição de narcóticos. Mais recentemente o governo lançou campanhas de repressão ao tráfico inaugurando postos de vigilância, e um heliponto no Maciço, com o intento de melhor controlar a criminalidade do local. No entanto, a polícia com suas ações truculentas dentro da comunidade contribui para um clima de insegurança - através de certas violências cotidianas, como ao tratar agressivamente os moradores, independente de terem relação ou não com o narcotráfico.

Nesse contexto as ações do Fórum se fortalecem, pois ao invés de discriminar e diferenciar utilizam um discurso agregador, onde as diferenças e competições políticas são neutralizadas e o apelo à unidade e à igualdade é fortalecido. São essas as bases do discurso democrático clássico, mostrando como a lógica do contrato entre as instituições, o governo, a Igreja e a sociedade civil, fortalece a representação da comunidade. Estas ações têm proporcionado maior tranqüilidade à população, com a percepção de que suas demandas estão sendo atendidas, 
independente dos vínculos partidários e das relações que estabelecem com os governos e setores da administração. Por isso vários moradores se permitem ir adiante, alentando novos processos decisórios, ampliando o seu círculo de relações e de influência - ou apenas trocando informações com outras comunidades e projetos da vizinhança, como foi constatado no grupo que entrevistamos no Morro da Queimada.

A ação dos católicos voltou-se principalmente a apoiar o Fórum e a proporcionar atividades extra-classe para os jovens da comunidade, através de um núcleo que oferece várias atividades de formação e lazer, com apoio financeiro das agencias católicas de ajuda internacional. Alguns desses jovens têm conseguido concluir seus estudos secundários e ingressar na Universidade. Várias outras obras de assistência social têm sido criadas no Maciço, recebendo fontes similares de apoio. Essa atuação granjeou grande prestígio nas comunidades e também entre as autoridades municipais e estaduais.

Todas as comissões criadas ao redor do Fórum têm tido grande efeito na organização e mobilização das comunidades do Morro, em sua busca pelo exercício da cidadania e usufruto dos direitos de acesso à cidade. A Comissão de Educação agrupa os diretores e professores das escolas que servem as crianças e adolescentes do Morro. Essas escolas realizam cursos e oficinas de arteeducação, curriculares e extra-curriculares, para promover e fortalecer as tradições e atividades artísticas existentes no Morro.

Além dos grupos carnavalescos, há no Morro muitas iniciativas culturais dispersas, que geralmente se encontram imersas na dominação tradicional, dos políticos clientelistas e do poder econômico difuso e clandestino do narcotráfico. A Comissão de Educação do Fórum assume como sua a missão de apoiar e transformar democraticamente a herança artístico-cultural das comunidades. E na UFSC formou-se uma equipe de pesquisadores e artistas voltados também a esse propósito, promovendo novas oficinas de arte, e apoiando as já existentes nas escolas, para fortalecer o "capital cultural" (Pierre Bourdieu) das comunidades, fortalecendo a capacidade e o poder reflexivo da comunidade frente aos dilemas enfrentados junto às ações tanto do poder municipal, como estadual e federal.

Grupos como esses têm participado das manifestações junto às autoridades, e na Assembléia Estadual, ao redor das conquistas e demandas do Fórum sobre a aplicabilidade e concretização da ZEIS, e pela participação e acesso dos moradores do Morro a seus direitos de cidadania. Cidadania compreendida como a ação de se experimentar e se apropriar dos espaços da cidade, transmutando as práticas que conferem valor apenas à cidadania representativa, existente somente no momento do voto. 


\section{Referências bibliográficas}

ADORNO, T.W. \& Horkheimer, M. A indústria Cultural: o esclarecimento como mitificação das massas. A dialética do Esclarecimento. Rio de Janeiro: Editora Zahar, 1985.

ADORNO, T.W. \& Horkheimer, M. A indústria cultural. In: Cohn, G. (Org.). Comunicação e indústria cutural. São Paulo: Companhia Editora Nacional, 1978.

ADORNO, T.W. \& Horkheimer, M. Conceito de Iluminismo. Coleção Os pensadores. São Paulo: Nova Cultural, 1996.

BOURDIEU, P. O poder simbólico. Lisboa: Deifel, 1989.

BOURDIEU, P. As regras da arte. São Paulo: Compainha das Letras, 1996.

BRANDÃO, C.R. A educação popular na escola cidadã. Petrópolis: Editora Vozes, 2002.

CANCLINI, N.G. Culturas híbridas. São Paulo: EdUSP, 2000.

CASTELLS, M. Materials for an exploratory theory of the network society. The British Journal of Sociology, 51(1): 5-24, 2000.

CHILTON, S. Situando o pós-modernismo na perspectiva do desenvolvimento moral-cognitivo. Civitas - Revista de Ciências Sociais, 2(2), 285-93, 2002.

ELIAS, N. Mozart, Sociologia de um gênio. Rio de Janeiro: Jorge Zahar Editor, 1995.

FERNANDES, C.S. Sociabilidade, arte e comunicação: o Movimento de Intercâmbio Cultural (MIAC) transfigurando o espaço público soteropolitano In: Práticas e Representações. Pp. 197-233. São Paulo: Humanitas/CERU, 2008.

FERNANDES, C.S. Sociabilidade, comunicação e política: a Rede MIAC como provocadora depotencialidades estético-comunicativas na cidade de Salvador. Tese de doutoramento. Florianópolis: Universidade Federal de Santa Catarina, 2005.

FRASER, N. \& HONNETH, A. Redistribution or recognition? A politicopholosophical debate. Londres: Verson Books, 2003.

HABERMAS, J. Facticidade e validade: Contribuições a uma Teoria do Discurso do Direito e do Estado Constitucional Democrático. Frankfurt: M.Suhrkamp, 1992. 
HABERMAS, J. Teoria de la acción comunicativa. Barcelona: Península, 1987.

HABERMAS, J. Moral consciousness and communicative action. Cambridge: Beacon Press, 1990.

HELLER, A. \& FEHÉR, F. A condição política pós-moderna, Rio de Janeiro: Civilização Brasileira, 1998.

HERSCHMANN, M. O funk e o hip-hop invadem a cena. Rio de Janeiro: Editora da UFRJ, 2000.

IKEDA, A.I. Música política: imanência do social. Tese de doutorado ECAUSP. São Paulo: Universidade de São Paulo, 1995.

JODELET, D. (Org.) Representações sociais, Rio de Janeiro, EdUERJ, 2001.

KRISCHKE, P. Aprendendo a democracia na América Latina. Atores sociais e mudança cultural. Porto Alegre: EdiPUC, 2003.

KRISCHKE, P. Note de recherche: L'apprentissage politique en zones d'éxclusion, de conflits et d'oranisation populaire. Politique et Sociétés (Montréal), 27: 81-97, 2008.

LANDOWSKI, E. Presenças do outro. São Paulo: Editora Perspectiva, 2002.

LACLAU, E. Os novos movimentos sociais e a pluralidade do social. Revista Brasileira de Ciências Sociais, 1(2): 41-7, 1986.

LASH, S. A Reflexividade e seus duplos: estrutura, estética, comunidade. In: A. Giddens, U. Beck \& S. Lash (Orgs.). Modernização reflexiva: política, tradição e estética na ordem social moderna. Trad. Magda Lopes. São Paulo: UNESP, 1997.

MAFFESOLI, M. A contemplação do mundo. Porto Alegre: Ofícios, 1995.

MARTINS, J.S. A sociabilidade do homem simples. São Paulo: Hucitec, 2000.

MELUCCI, A. Esfera pública e democracia em la era de la información. Metapolítica, 3(9): 57-67, 1999.

MORIN, E. \& KERN, B. Terra-Pátria. Porto Alegre: Sulina, 1995.

SHUTZ, A. Fenomenologia del mundo social (Introducción a la sociologia compreensiva). Trad. E.J. Pietro. Buenos Aires: Paidós, 1972. 